\title{
Invitation to the 29th scientific meeting of the International Society of Hypertension: ISH2022 Kyoto
}

\author{
Hiroshi Itoh ${ }^{1} \cdot$ Kazutoshi Miyashita ${ }^{1}$
}

Received: 4 October 2021 / Accepted: 6 October 2021 / Published online: 24 November 2021

(c) The Japanese Society of Hypertension 2021

On behalf of the organizing committee, it is great pleasure to invite you to the 29th Scientific Meeting of the International Society of Hypertension (ISH2022), which will be held from October 12 to 16, 2022, at the Kyoto International Conference Center. The theme is "The Wisdom for Conquering Hypertension" (Fig. 1). This meeting will take place at the same time and in the same place as the 44th Annual Meeting of the Japanese Society of Hypertension (JSH2022). We want to hold the meeting on-site and are preparing to hold in a hybrid format that will provide online content. The utilization of an online format will promote the participation of young researchers, students and participants from developing countries, who have difficulty in attending on-site.

By holding ISH2022, our friends and colleagues from all over the world will communicate in person and share the scientific progress in conquering hypertension that they have made. Members of the JSH or ISH shall lead the cooperation of all medical staff involved in hypertension care and explore novel approaches to conquer not only hypertension but also various health problems around the world. The number of participants is estimated to be 4500 people. We are planning to prepare travel grants for 300 young participants, poster awards for developing countries, and excellent presentation awards. Support has been provided by various organizations that cooperated with us at the time when the invitation was issued, including the Ministry of Health, Labor and Welfare in Japan and the Japan Medical Association. The Science Council of Japan, which is one of the leading organizations for the promotion of scientific research in Japan under the direct control of the Cabinet Office, has officially decided to support ISH2022, and the participation of the Imperial Family of Japan is expected.

Kazutoshi Miyashita

miyakaz@z6.keio.jp

1 Department of Endocrinology, Metabolism and Nephrology, Keio University, School of Medicine, 160-8582 Tokyo, Japan
To share the world's most advanced knowledge on hypertension research, the scientific programs of ISH2022 focus on three main topics related to hypertension: Food (food and nutrition), Move (exercise and fitness) and AI (artificial intelligence and digital health) (Fig. 2). The participants are expected to include not only representatives of academia and medicine but also various companies and local governments. In addition to the three topics, ISH2022 covers the following categories:

1. Hypertension for Sustainable Development Goals (SDGs) Toward 2030 World (climate, disaster and mental health)

2. Global Health and Hypertension with Diversity (economical difference and medical resources)

3. Life-Course and Hypertension (preconception, developmental origins of health and disease $(\mathrm{DOHaD})$ and oncohypertension)

4. Super-Aged Society and Hypertension (sarcopenia, dementia and social capitals)

5. Hypertension Next-Generation Therapy (renal denervation and single compound pills)

6. Convergence of Communicable Diseases and NonCommunicable Diseases (NCDs)

7. Japan Method for Conquering Hypertension (hypertension zero town)

8. Pathophysiology of Hypertension: Chronicle to the Future

9. Blood Pressure Measurement: Conventional and Future

10. Imaging and Biomarker for Hypertension Management

11. Hypertension Reigning Over Systemic Diseases

12. Hypertension and Epigenome

The program committee members are working intensively to make ISH2022 innovative, impressive and informative for participants, and they are inviting outstanding minds from all over the world. The following special guests have been scheduled to give lectures at ISH2022 Kyoto: 


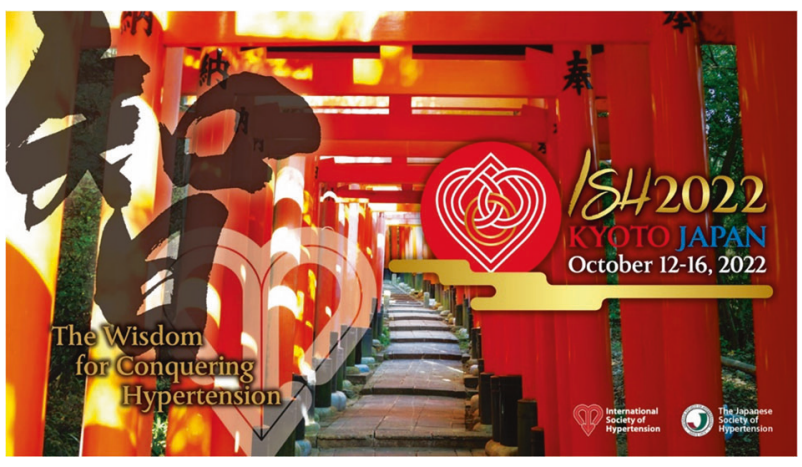

Fig. 1 The official poster of ISH2022 Kyoto. The background is "Senbon Torii", which is a path with the one thousand wooden gates of the Fushimi Inari shrine in Kyoto. The Chinese character pronounced as "chi" on the left side of the photo means "wisdom". The poster represents a wish for ISH2022 Kyoto to be filled with the wisdom for conquering hypertension

Dr. Victor J. Dzau (President of the United States National Academy of Medicine)

Dr. Richard P. Lifton (President of Rockefeller University)

Dr. Shinya Yamanaka (Professor of Kyoto University, 2012 Laureate of the Nobel Prize in Physiology or Medicine, who discovered induced pluripotent stem (iPS) cells)

Dr. Hiroo Imura (Former President of Kyoto University. Former Chairman of the Foundation for Biomedical Research and Innovation in Japan)

By sharing our multidisciplinary wisdom regarding hypertension and related diseases with each other, ISH2022 encourages the creation of novel diagnostics, prevention and treatment of hypertension and related diseases, generating a new paradigm for our shared mission, to conquer hypertension. ISH2022 warmly welcomes young researchers and participants

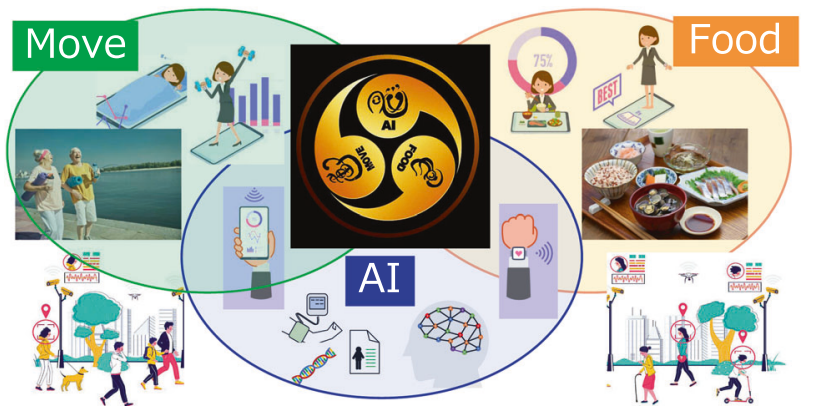

Fig. 2 The three main topics of the ISH2022. The three main topics of the ISH2022 scientific program related to hypertension: Food (food and nutrition), Move (exercise and fitness) and AI (artificial intelligence and digital health)

from developing countries by offering discounted registration fees and special awards. Through participation in ISH2022, we strongly believe that participants will broaden their knowledge, expertise and wisdom regarding hypertension by learning from the best speakers and enjoying Japanese hospitality.

We look forward to meeting you in Kyoto in 2022.

Please visit the official website for details: https://www. ish2022.org/

Hiroshi Itoh (Keio University. President of ISH2022, Vice President of the ISH, Former President of the JSH)

Kazutoshi Miyashita (Keio University. Secretary General of ISH2022).

\section{Compliance with ethical standards}

Conflict of interest The authors declare no competing interests.

Publisher's note Springer Nature remains neutral with regard to jurisdictional claims in published maps and institutional affiliations. 